

\section{IEEE 4th International Forum on Research and Technologies for Society and Industry}

(RTSI)

(C) 2018 IEEE. Personal use of this material is permitted. However, permission to reprint/republish this material for advertising or promotional purposes or for creating new collective works for resale or redistribution to servers or lists, or to reuse any copyrighted component of this work in other works must be obtained from the IEEE.

Additional copies may be ordered from:

IEEE Service Center

445 Hoes Lane

Piscataway, NJ 08855-1331 USA

+1800678 IEEE (+1 800678 4333)

$+17329811393$

+17329819667 (FAX)

email: customer-service@ieee.org

Copyright and Reprint Permission: Abstracting is permitted with credit to the source. Libraries are permitted to photocopy beyond the limit of U.S. copyright law for private use of patrons those articles in this volume that carry a code at the bottom of the first page, provided the per-copy fee indicated in the code is paid through Copyright Clearance Center, 222 Rosewood Drive, Danvers, MA 01923. For reprint or republication permission, email to IEEE Copyrights Manager at pubs-permissions@ieee.org. All rights reserved. Copyright @2018 by IEEE.

ISBN: CFP18C29-ART

Part Number: 978-1-5386-6282-3 


\section{Table of contents}

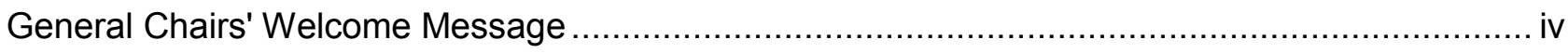

Technical Program Committee Chairs' Welcome Letter .........................................................

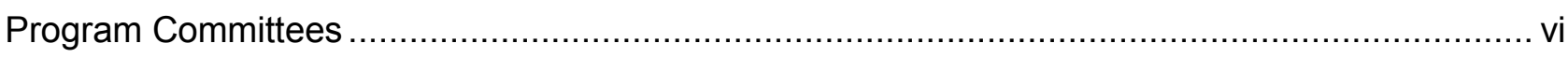

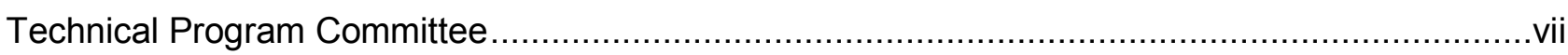

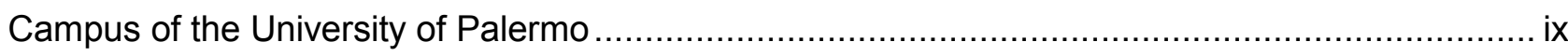

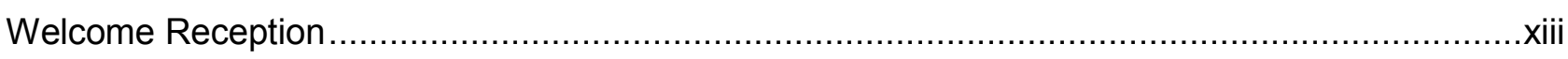

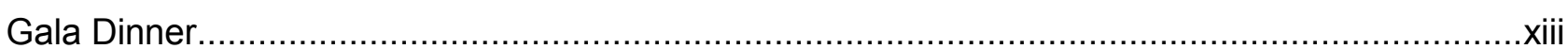

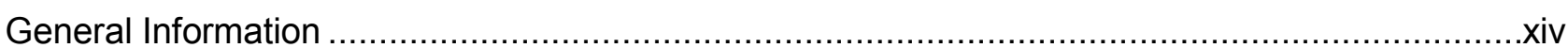

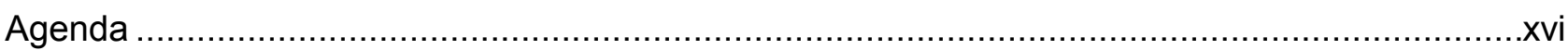

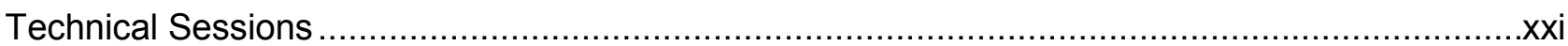




\section{General Chairs' Welcome Message}

It is our great pleasure to welcome you to the Fourth Edition of the International IEEE Forum on Research and Technologies for Society and Industry (RTSI) that is taking place in Palermo, Italy, from Monday September 10th until Thursday September 13th, 2018. The RTSI is the flagship conference of the IEEE Italy Section and represents the annual gathering of researchers and industry professionals in the field of electrical, electronic, and information science and engineering.

The theme chosen for the 2018 edition of RTSI is "Innovation to shape the future", a challenge based on three areas of great interest and relevance: Sustainable development for cities and environment, Smart emerging technologies for Industry 4.0, ICT for future networks. Undoubtedly, innovation in electrical, electronic, and information science and engineering has fundamentally transformed our society in recent decades and the pace of change can only be described as disruptive. Not only technologies, but also economies and societies are continually shaped by innovation. Based on these evidences, the core purpose of RTSI is to foster technological innovation and excellence in the fields of electrical, electronic, information science and engineering.

Specifically, the main purposes of the event are:

- to promote and to strengthen partnerships and cooperation between academia and industry;

- to increase the public's understanding and awareness of how engineering and technology can positively affect quality of life;

- to promote discussion between the research community and government bodies about effective and successful research policies;

- to disseminate recent advancements, discoveries and applications;

- to discuss ideas and to promote cooperation between researchers working in different research areas.

RTSI includes panels, technical sessions, tutorials, special events and exhibitions, as reported in detail in the technical program. This year we have, for the first time, the technical sponsorship of IEEE Region 8 with three European Sections (France, Switzerland and UK\&Ireland) beside numerous technical sponsorship from chapters and university association.

The Award Ceremony, this year will be enriched with awards from the Section, Chapters and sponsored by industries. ST contributes to the Young professional competition and the corporate sponsor ABB supports financially six prestigious awards for $\mathrm{PhD}$ and Master thesis.

In addition to the stimulating program of the conference, Palermo, Italian Capital of Culture 2018, with its tourist attractions, the quality of its cuisine, and historical monuments, is an unforgettable place. We hope you get a chance to visit this beautiful city.

We would like to give a warm welcome to all the participants to RTSI and look forward to meeting you over the four days of the forum.

Enjoy RTSI 2018 @Palermo!

Warmest Regards,

Tiziana Tambosso

Guido Ala 


\section{Technical Program Committee Chairs' Welcome Letter}

The Technical Program of the fourth edition of RTSI is very rich: it includes 27 technical sessions with 138 contributed papers, 29 invited talks and keynote speakers, five tutorials on very hot topics, 3 panels in which industries and universities debate on topics like:

- Smart energy systems for smart city districts,

- Smart Technologies \& Best Practices for Industry 4.0 and Digital Transformation

- ICT at the service of the citizen: best practices and business cases;

and a Special meeting on innovative start up \& entrepreneurs in which incubators, associations and foundations can share their ideas for nurturing a favourable ecosystem toward an altruistic model of economy.

In addition the program includes:

- a Young Professional Demo Competition with the focus on innovative prototype implementations, systems and technologies in a broad range of fields that include all the themes belonging to RTSI;

- a WIE event: titled "Steering girls to STEM", organized by the IEEE Women in Engineering Italian Affinity Group in cooperation with other two Italian Associations AICA and AEIT;

- The IEEE Student Branch Meeting organized by the IEEE Italy Section SB coordinator with the objective to bring together the Italian Student Branches sharing their best practices and also offering the students the opportunity to follow an international and interdisciplinary conference;

- The Meeting with Industries with the objective to inform all participants of the initiatives that IEEE Region 8 (Europe, Africa and Middle East) and IEEE Italy Section are promoting in favor of industries. Such event will include presentations by ST, an industry already involved in joint programs with IEEE, and by IEEE France Section reporting on their actions for industries. The meeting will end with an open discussion with the participant industries on new ideas and proposals of common interest.

We would like to thank all technical sponsors for their support and promotion, the track chairs and session chairs for their essential work of organization and management of the technical sessions, all the reviewers who assured a high quality of papers. Special thanks are also due to the chairs of the tutorial, panels and YP Event for their valuable work.

Last but not least, a special thank to the organizing team of the University of Palermo whose effective contribution and enthusiastic work ensured the realization of this event.

Hope you all can enjoy RTSI 2018!

With our best regards,

Bernardo Tellini

Gaetano Zizzo 


\section{Program Committees}

General Chairs:

Guido Ala, University of Palermo

Tiziana Tambosso, IEEE Italy Section Chair

\section{Steering Committee Chairs}

Ermanno Cardelli, IEEE Italy Section Past-

Chair

Dario Petri, IEEE Italy Section National

Association Liaison Committee Coordinator

\section{Steering Committee}

Pasquale Daponte Research Association GMEE

Paolo Ciancarini, Research Association GRIN

Paolo Bassi, Research Association SIEM

Alfredo Testa, Research Association GUSEE

Maria Chiara Carrozza, Research Association

GNB

Ciro Attaianese, Research Association

CMAEL

Fabio Villone, Research Association ET

Ali Hessami, UK\&Ireland Session Chair

Frederique Vallee, Chair France Section

Maria-Alexandra Paun, Switzerland Section

Chair

Luigi Rovati, RTSI 2017 Chair

Technical Program Committee Chair

Bernardo Tellini, IEEE Italy Section Vice-Chair

Technical Program Committee co-Chair

Gaetano Zizzo, University of Palermo

Track Chairs

TRACK 1: SUSTAINABLE DEVELOPMENT

FOR CITIES AND ENVIRONMENT

Fabio Massaro, University of Palermo

Giambattista Gruosso, IEEE Italy Section

TRACK 2: SMART EMERGING

TECHNOLOGIES FOR INDUSTRY 4.0

Mauro Mosca, University of Palermo

Leopoldo Angrisani, IM Chapter chair

TRACK 3: ICT FOR FUTURE NETWORKS

Dajana Cassioli and Fabrizio Granelli, COM/VT Chapter Chair

Secretariat

Salvatore Favuzza, Marco Trapanese,

University of Palermo

\section{Tutorial Chair}

Salvatore Favuzza, University of Palermo

Exhibition Chair

Salvatore Favuzza, University of Palermo

Fabio Montagnino, Consorzio ARCA

Publicity Chair

Vincenzo Di Dio, University of Palermo

Publication Chair

Daniela Proto, IEEE Italy Section

Special meeting for innovative start-up \& entrepreneurs

Vincenzo Di Dio, University of Palermo

Giovanni Perrone, President PNICube

Pietro Erratico, IEEE Italy Section Afl

Coordinator

Women in engineering affinity group meeting

Dajana Cassioli, IEEE Italy Section WIE-AG

Chair

\section{Young Professional Demo Competition}

Event

Ferdinando Nunziata, IEEE Italy Section, YPAG Chair

\section{Student Activity}

Marco Santambrogio, IEEE Italy Section SAC

Coordinator

Treasurer

Sergio Rapuano IEEE Italy Section Treasurer

\section{Organization Committee}

Salvatore Basile, University of Palermo

Riccardo Burlon, University of Palermo

Vincenzo Di Dio, University of Palermo

Luigi Dusonchet, University of Palermo

Salvatore Favuzza, University of Palermo

Elisa Francomano, University of Palermo

Graziella Giglia, University of Palermo

Mariano Giuseppe Ippolito, University of

Palermo

Fabio Massaro, University of Palermo

Pietro Romano, University of Palermo

Gaetano Zizzo, University of Palermo

\section{Webmaster}

Gabriele Adamo, University of Palermo 


\section{Technical Program Committee}

Marie-Hélène Abel, Université de Technologie de Compiègne

Nicola Accettura, LAAS-CNRS

Gabriele Adamo, University of Palermo

Antonio Agresti, University of Rome Tor Vergata

Andrea Alaimo, Kore University of Enna

Gioacchino Alotta, University of Palermo

Leopoldo Angrisani, University of Naples Federico

II

Olga Barrera, Oxford Brookes University

Jean-Paul Barthes, Université de Technologie de

Compiègne

Luca Bascetta, Politecnico di Milano

Ivano Benedetti, University of Palermo

Giuseppe Bernieri, University of Padua

Marco Bertini, Università di Firenze

Giuseppe Bianchi, University of Rome "Tor

Vergata"

Mauro Bologna, University of Tarapaca

Sergio Bruno, Politecnico di Bari

Alice Buffi, University of Pisa

Andrea Buono, Parthenope University of Naples, Napoli

Alessandro Burgio, University of Calabria

Claudio Calì, Università di Palermo

Angelo Cangelosi, Adaptive Behaviour and

Cognition Research Group

Sara Carcangiu, University of Cagliari

Ermanno Cardelli, University of Perugia

Angelamaria Cardone, University of Salerno

Giuseppe Caruso, Università di Palermo

Dajana Cassioli, University of L'Aquila

Stefano Cattini, University of Modena and Reggio

Emilia

Maurizio Cellura, Università di Palermo

Kristopher Chandía, University of Tarapacá

Franco Chiaraluce, Università Politecnica delle

Marche

Luca Chiaraviglio, University of Rome Tor Vergata

Alfonso Cino, University of Palermo

Giovanni Cipriani, University of Palermo

Salvatore Coco, University of Catania

Francesco Conte, University of Genova

Giuseppe Conte, Università Politecnica delle

Marche

Francesca Coppola, EDAS
Valeria Corcione, University Parthenope

Mickael Coustaty, University of La Rochelle

Fabio Crescimbini, Università ROMA TRE

Isodiana Crupi, University of Palermo

Filippo D'Ippolito, University of Palermo

Pasquale De Falco, University of Naples

Parthenope

Marco Di Benedetto, C-PED, Center for Power

Electronics and Drive, University Roma Tre

Luca Di Cecilia, University of Modena and Reggio

Emilia

Gerardo Di Martino, University of Naples Federico

II

Luigi Pio Di Noia, University of Naples Federico II

Maria Luisa Di Silvestre, University of Palermo

Alessio Di Simone, University of Naples, Federico II

loanna Dionysiou, University of Nicosia

Antonio Faba, University of Perugia

Nicolò Facchi, University of Trento

Lorenzo Faggioni, Sirm

Adriano Fagiolini, University of Palermo

Giuseppe Failla, Università di Reggio Calabria

Matteo Ferroni, Bottega52

Viviana Figà, Istituto Euro-Mediterraneo di Scienza

e Tecnologia

Lucie Finez, University of Burgundy

Sara Foresti, Università degli Studi di Milano

Mauro Franceschelli, University of Cagliari

Fabio Franchi, University of L'Aquila

Pierluigi Gallo, University of Palermo

Omar Garcia Crespillo, German Aerospace Center (DLR)

René Garello, IMT Atlantique

Angelo Genovese, Università degli Studi di Milano

Fabrizio Granelli, University of Trento

Francesco Gringoli, University of Brescia

Francesco Guarino, University of Palermo

Thomas Hammarstroem, Chalmers University Of

Technology

Bo Huang, Southampton University

Antonino Imburgia, University of Studies of

Palermo

Fernanda Irrera, University of Roma La Sapienza

Jean-Paul Jamont, Univl. Grenoble Alpes

Anne Johannet, IMT Mines Alès, Université de Montpellier 
Hedi Karray, ENIT

Koteswararao Kondepu, Sculoa Superiore Sant'Anna

Marco La Cascia, University of Palermo

Francesco Lanza, University of Palermo

Francesco Lassandro, EDAS

Antonino Laudani, University of Roma Tre

Giuliana Leone, Università degli Studi di Palermo

Vincenzo Li Vigni, Prysmian

Alessandro Lidozzi, C-PED, University Roma Tre

Patrizia Livreri, University of Palermo

Liliana Lo Presti, Università degli Studi di Palermo

Michela Longo, Politecnico di Milano

Sonia Longo, University of Palermo

Nicola Francesco Lopomo, University of Brescia

Gabriele Maria Lozito, Roma Tre University

Giuseppe Lullo, University of Palermo

Roberto Macaluso, University of Palermo

Marco Maccioni, University of Rome Sapienza

Massimo Macucci, University of Pisa

Juliette Marais, IFSTTAR, LEOST

Paolo Marconcini, University of Pisa

Andrea Marotta, University of L'Aquila

Mirko Marracci, University of Pisa

Stefano Massucco, University of Genova

Ivan Mazzetta, Sapienza University of Rome

Manuel Mendes, Universidade Nova de Lisboa

Alessio Merlo, DIBRIS - University of Genoa

Mauro Migliardi, University of Padova

Alberto Milazzo, Università di Palermo

Salvo Mirabella, Università di Catania

Marina Mistretta, Università Mediterranea di Reggio

Calabria

Paolo Monti, KTH Royal Institute of Technology

Mauro Mosca, University of Palermo

Fabio Mottola, University of Naples Federico II

Paolo Nepa, University of Pisa

Gabriele Oliva, University Campus Bio-Medico of

Rome

Jessica Smeralda Oliva, University of Palermo

Calogero Orlando, Kore University of Enna

Pietro Pala, Università di Firenze

Lucia Pallottino, University of Pisa

Domenico Panno, Università di Palermo

Antonino Parisi, University of Palermo
Alberto Pasquarelli, University of Ulm

Maria-Alexandra Paun, Swiss Federal Institute of Technology (EPFL)

Riccardo Pernice, University of Palermo

Carlo Petrarca, Naples University

Silvia Maria Pietralunga IFN-CNR

Christian Pilato, Università della Svizzera Italiana

Sabino Pipolo, University of Nottingham

Claudio Pisa, CNIT

Davide Poli, University of Pisa

Daniela Proto, University of Naples Federico II

Giovanni Puglisi, University of Cagliari

Francesco Pulsinelli, Roma Tre University

Alessandro Quarto, MYHERMES Srl

Simone Quondam Antonio, University of Perugia

Anna Maria Raspolli Galletti, University of Pisa

Francesco Riganti Fulginei, Roma TRE University

Daniele Ronsivalle, Università di Palermo

Luigi Rovati, University of Modena and Reggio

Emilia

Giuseppe Ruello, University of Naples Federico II

Alessandro Ruvio, University of Rome La Sapienza

Claudio Sacchi, University of Trento

Alessandro Salvini, Roma Tre University

David Scaradozzi, Università Politecnica delle

Marche

Antonino Sferlazza, Univerity of Palermo

Federico Silvestro, University of Genova

Luca Spalazzi, Università Politecnica delle Marche

Salvatore Stivala, University of Palermo

Violet Syrotiuk, Arizona State University

Szymon Szott, AGH University of Science and

Technology

Bernardo Tellini, University of Pisa

Federico Tonini, Università di Bologna

Emiliano Tramontana, University of Catania

Quynh Tran, University of Palermo

Silvia Ullo, Università degli Studi del Sannio

Damiano Varagnolo, Luleå University of

Technology

Ana Lucia Varbanescu, University of Amsterdam

Filippo Zerboni, Mobi Med

Gaetano Zizzo, University of Palermo 


\title{
Cities and skills for integration: what can urban planning do? Experiences and reflections between public spaces and collective interest for urban and community (smart) resilience
}

\author{
Daniele Ronsivalle \\ Dept. of Architecture \\ University of Palermo (UNIPA) \\ Palermo, Italy \\ daniele.ronsivalle@unipa.it
}

\begin{abstract}
Immigration and integration of foreign communities is a condition that strongly affects the form and the meaning of public space. In contexts that are new to the phenomenon, there may be an occasion to revise the protocols and models for the development of new spatial relationships, based on the presence of communities that are no longer homogeneous. The theme of urban regeneration due to the presence of migrant communities has been addressed in various ways and from different points of view, often focusing on the creation of urban spaces capable of improving livability, rarely with the creation of integration processes or the construction of new urban identities. However, a resilient point of view, in ecological and social terms, can allow a new perspective on the way in which the multiple presence of communities that are no longer "original" has radically changed the sense of urban space. This contribution reports some experimental experiences on how the city and the community in progress can develop a coordinated system of actions able to act on the theme of reception and integration, working in the perspective of urban resilience and acting on social policies and on the spatial relevance of integration programs. Through cooperative learning, in a process of applied research with experts in the social habit of four Sicilian cities (Ragusa, Catania, Caltanissetta, and Palermo) the tested integration policies will be evaluated not in terms of melting pot, but in terms of identifying identity spaces able to build a sense of community.
\end{abstract}

Keywords—public space; public interest; social integration

\section{THE THEORETICAL FRAMEWORK}

\section{A. Public spaces as a tangible manifestation of public interest}

The first theoretical component of the research on the theme "integration, city and public space" described in this contribution is related to the difficult re-composition of public interest, where the multiplicity of settled communities increases the difficulty of recomposing the local public interest.
The challenge of reconciling the benefits of common public interest with the diversity that derives from the questions and needs of the communities living side by side in the same city, is strengthened thanks to the role of the planner as a local mediator in bottom-up processes, in which the planner serves the public interest by negotiating a sort of multicultural pluralism, based on the action of cultural mediation and communication in the planning process.

In this condition in which the public interest is reconfigured in the bottom-up processes, we range from a public interest held and represented exclusively by the institutional subjects who bring a vision of equilibrium of the shareholders' needs to a broader vision of the complex interaction between all the stakeholders, bearer a "power" of action, and subjects belonging to networks of shared interests (netholders).

The geometries of these relationships between subjects are extremely variable depending on the situations, which the "plan" must identify and use as driving structures.

Amin and Thrift [1] highlight this design relationship between public space and public sphere, underlining the democratic force of a public space and, citing Tajbakhsh [2], recall the relevance of hybridization of identities to come to the formulation of a new reflective, mature, and contingent self.

Everything is about filling the efficiency of public policy in the urban territories of the hybrid communities and of the new non-original communities: Lewis Mumford's vision of the city made (?) of urban interactions in a public space that is extension of the domestic life of the medieval city becomes a design goal of the multi-ethnic city, or multi-community.

\section{B. Resilience and communities}

To interpret the vision of the community composition and the respect of everyone's "right to the city" in a contemporary way, research worked on the concept of urban resilience, but 
with deep roots, in parallel with the development of the concept of sustainability development.

From its origins in the thinking of ecological systems in the $60 \mathrm{~s}$ and early 70s, resilience has progressively gained importance. Because of the unclear definition and malleability of the concept, it has been developed and adapted to a wide range of disciplines including engineering, ecology, physics, geography and even business management and psychology as in Holling [3]

Regarding the city, the thought of resilience has advanced and has been considered according to three separate readings:

- a traditional ecological perspective based on engineering thought, subsequently labeled as an engineering perspective, static and tending to a univocal equilibrium;

- a more recent ecological perspective, which does not take into consideration the human community;

- a socio-ecological perspective.

By the end of the '70s, urban sociologists and sociologists began to recognize that social systems - in particular human settlements - are not isolated systems, but inextricably linked to each other and to the ecosystems on which they depend. This way of thinking, as in Folke [4], has led to the development of socio-ecological systems (SES).

Thinking on resilience in this approach has led to the development of socio-ecological resilience that "incorporates the idea of adaptation, learning and self-organization" in addition to its ability to withstand disturbing conditions and thus captures the meaning of human potential to transform his living environment [4]. For Carpenter et al. [5], socioecological resilience can be measured by (?) three main characteristics:

1. the amount of disturbance that a system can absorb and can remain in the same state;

2. the degree in which the system is able to self-organize itself;

3. the ability to build and increase the ability to learn and adapt.

This approach to resilience further challenges the "balancebased" notion of engineering and ecological concepts alternatively by seeing resilience as a process of evolution or transformation, trying to turn challenges into opportunities, as it fully recognizes that systems are in one constant change, even when they are not threatened by disturbances [6]. Scholars also defined that as the ability of the system to adapt to changing conditions, and therefore sometimes refer to socioecological resilience as the capacity for evolutionary recovery [7], [8].

From its origins, the application of resilience within the urban environment has undergone various changes, although this evolution may be more connected to the changing notions of the urban environment itself, than to changes in the definition of resilience. The disorders that cities have to face, manifest themselves in different ways and, consequently, resilience is an evolving concept.

\section{NUMBER OF EQUILIBRIUMS

\section{Engineering resilience} one speed of return to the single
equilibrium

- predictable

- external

- shocks

\section{- resistance and recovery}

- efficiency, predictability

\begin{tabular}{|c|c|c|c|c|}
\hline $\begin{array}{l}\text { Ecological } \\
\text { resilience }\end{array}$ & multiple & $\begin{array}{l}\text { magnitude of shocks that } \\
\text { can be absorbed, before the } \\
\text { threshold to enter a new } \\
\text { equilibrium is crossed, as well } \\
\text { as degree of self-organisation } \\
\text { and capacity for learning }\end{array}$ & $\begin{array}{l}\text { - predictable and } \\
\text { unpredictable } \\
\text { - external } \\
\text { - shocks }\end{array}$ & $\begin{array}{l}\text { - persistence } \\
\text { - adaptability, flexibility } \\
\text { - resourcefulness, } \\
\text { efficiency, diversity }\end{array}$ \\
\hline
\end{tabular}

\begin{tabular}{|c|c|c|c|c|}
\hline $\begin{array}{l}\text { Social- } \\
\text { ecological } \\
\text { resilience }\end{array}$ & $\begin{array}{l}\text { none, } \\
\text { continuously } \\
\text { changing }\end{array}$ & $\begin{array}{l}\text { magnitude of shocks and } \\
\text { stresses that are continuously } \\
\text { absorbed, as well as advanced } \\
\text { degree of self-organisation } \\
\text { and capacity for learning by } \\
\text { social-ecological svstems }\end{array}$ & $\begin{array}{l}\text { - predictable and } \\
\text { unpredictable } \\
\text { - internal and external } \\
\text { - shocks and stresses }\end{array}$ & $\begin{array}{l}\text { - persistence } \\
\text { - adaptability, flexibility } \\
\text { - human potential } \\
\text { to transform its } \\
\text { surroundings (human } \\
\text { agency) }\end{array}$ \\
\hline
\end{tabular}

Fig. 1. Three ways to interpret resilience (UN habitat, 2017) 
We can certainly state on the basis of multidisciplinary indications on the issue that resilience is seen as a process, a state and a quality [9].

Therefore, cities function are complex, interdependent and integrated socio-ecological systems: it is fundamental to understand how resilience-based planning, development and management can protect lives, resources and maintain function continuity through any shock or stress.

However, adding the adjective "resilient" to urban transformation projects is not enough: programs providing resilient health care, resilient water supply, resilient societies or climate change resilience do not improve the overall resilience of a city if faced separately and as a trend. Only by observing the system as a whole, cities will be able to successfully respond to the impacts of economic, social, political or natural events and avoid displacements, injustices, overwhelmed urban services or a weakened ability to manage cities properly.

In this context, much literature focuses on a plethora of shocks and stress, from natural disasters to civil conflicts. The result is a wide range of studies that disruptive impacts on food and water security, energy supply, agricultural production, transport, but also on social inclusion and migration, crucial content of this contribution.

This overview on the conceptualization of resilience from a theoretical point of view has revealed that resilience is seen firstly as a framework for thinking about achieving common goals within urban contexts in which new solutions to ancient conflicts need to be found.

\section{The spatial vision}

Collective interest and social resilience need a strong catalyst to be able to define how the community is ready for the shock of repopulation or the arrival of new communities, for the functional transformation from the bottom of an urban space or to the intrusion into the tissues - urban and social - of alien groups.

To understand why space is relevant in the development of the collective interest, let's just think about some historical events of dramatic ones such as earthquakes, in historical times such as Val-di-Noto in 1693, or strong policies of a managerial and centralizing type such as the repopulation of Inland Sicily through the status of jus populandi in the $16^{\text {th }}, 17^{\text {th }}$ and $18^{\text {th }}$ centuries, which in some cases in practice led to the forced displacement of entire human groups.

If these events were narrated by the columns of contemporary newspapers rather than by historians, probably the controversy over the wrong localizations or the violence exerted on the communities uprooted from their lands of origin would prevail over the completed or not completed outcome of development.

In these places, created in drama or violence, there is always a square, a public space designed for the whole community, but not like the space of the lodges in the medieval city, belonging to a single corporation: the square is synecdoche of vision space of these new urban places, outcome of situations in which the birth of a new interest of the community also passes through its ability to adapt to new urban contexts.

The square is everything: «... the model of city with which Europe has identified its history and its culture cannot be configured in a lasting manner through a clear opposition between the historic center, the suburbs and the suburbs more or less distant; between pedestrians and motorists, between activities related to culture and leisure and production. Our squares [...] testify each time both terms of these oppositions. [...] They make sense only in the context of the life of the city that generate them». [10]

The square is the key example of how public space contributes to reformulating the social conditions of a community.

\section{Relations with ICT and urban smartness}

About the relation of ICT and smartness, the concept of "the smartest person is the room" [11] is a major element to understand what way the research worked and how the planner can approach the integration policies.

Also, in social policies for integration and migrant communities, generally, knowledge is not only a shared

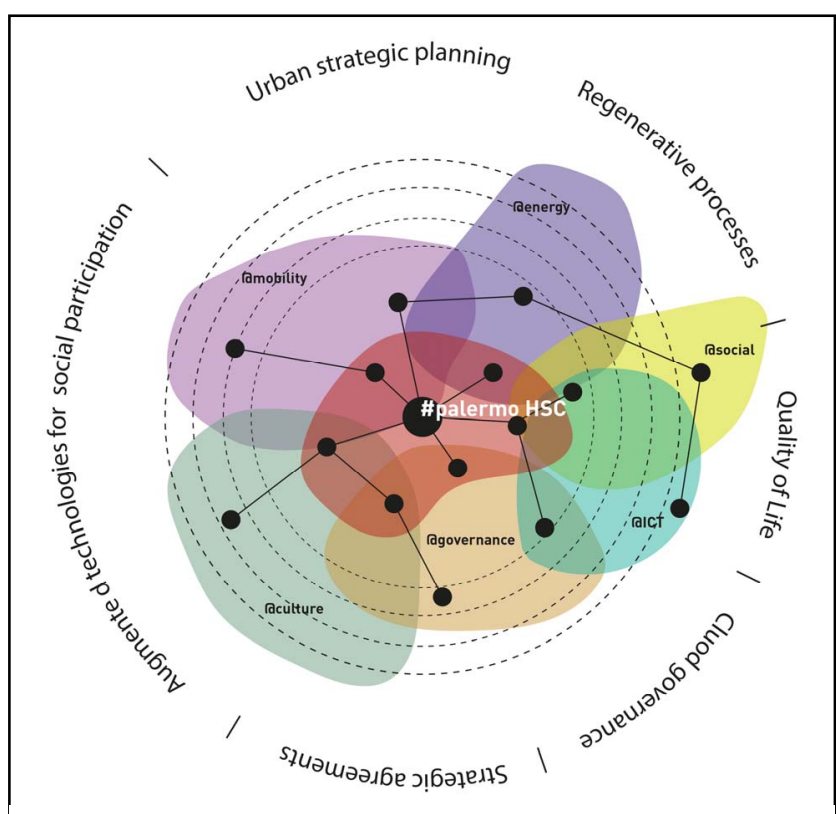

Fig. 2. Human Smart City Nebula. The classic hexagonal Smart City model has taken on a new structure to integrate the choices for urban regeneration. It has become a cloud of interactions, within which it is possible to retrace the routing function of the workshop laboratories and the interlacing of research functions and applicative goals. The nodes in the gravitational field of the Human Smart City model (\#HSC) are connected on the issues of the smart city framework, but the \#HSC model discovers new interactions. Elaboration by Author.

knowledge of urban places and uses, but it is almost component of urban places, it's widespread and devoid of a truthfulness validated $a$ priori so that also false information can become true. 
The smartest room, therefore, is not a decisive and positive place, but it needs criteria and clear assessments, and tools to prevent false data from becoming true needs of urban communities, by a deliberate will.

The commitment to human smart city is connected to social activities for integration of new citizens: the logics of the connections between human Smart City and urban strategies see to a smart city model like a nebula [12].

The nebula model, as a rethinking of the hexagonal smart city model, contributes to co-generation solutions: the innovative components contribute to the generation of new urban transformations and it is often a proactive engine, with the aim of enabling technology.

In synthesis, the need to adopt a new interpretive paradigm that allows grasping, in real time, the changes taking place and to define actions able to keep the evolution of the urban system within negentropic sustainability trajectories is now necessary to the undeferrable construction of a new technical-disciplinary planning vision, connecting places, resources and community, in real and digital ways.

\section{EXPERIMENTATION: IMMIGRATION AND RECEPTION IN THE BORDER AREAS}

The 2014-2020 Migration and Integration Asylum Fund, co-funded by the European Union and managed by the Ministry of the Interior, has financed the project called "Com.In.3.0. Skills for integration" which involves the Italian regions in the convergence area and works in Sicily, under the coordination of the Pedro Arrupe Political Training Institute of Palermo, on four particularly heterogeneous urban realities:

- Palermo, with its communities of migrants stabilized in the urban context, organized in a consultation of local communities, with a structured reception policy on the multiculturality of its history, but also with problems of urban coexistence, criminality and mutual segregation between communities (including indigenous ones);

- Catania, with similar situations, plus the difficulty of some processes of emergence of underwater activities, despite the efforts of the cultural mediators;

- Ragusa, a borderland of Europe, often a place of transit and, therefore, a place of non-integration;

- Caltanissetta, new to the phenomenon of immigration and, therefore, in terms of (?) being able to take advantage of what has already been done in other urban areas.

Within this project and in these four cities, a training course for operators in the social field was set up, to build networks of partners for the construction of innovative solutions.

The writer has promoted, in the four training contexts, four workshops with the operators to draw actions useful for the reconfiguration of the public space, starting from a greater awareness among the experts present sitting at the working tables of the relevance of the spatial component to improve integration actions.

The concept of cooperative learning workshops is to involve the communities because their integration starts from the rediscovery of the self-communication ability à la Castells and the self-awareness of urban life.

\section{A. starting data}

The territories in question are not among those in Italy with a greater presence of foreigners; it is known that the flow involves a transition from South to North with some specific situations beyond the Strait of Messina, as in Riace (20\% of foreigners on total population). The ISTAT census annual report for 2017 shows 3.94\% in Palermo, 4.04\% in Catania, $5.3 \%$ in Caltanissetta, $6.13 \%$ in Ragusa.

As mentioned above, however, the perception by the operators involved in the project is that the presence in the capital is more structured and organized in the forms of a permanent place of life, as evidenced by the existence of a basic assembly structure, the so called "Consulta delle Culture" composed by 21 representatives of all foreign residents and divided according to their geographical area of origin, the majority of which are Indo-Asians. There is also a magazine of interculturality promoted by the City.

The operators who proposed themselves to carry out the activity, by an open call, come from public institutions, the third sector and professional autonomous activities.

None of the participants, as evidenced by the data in table I, have in their training a spatial vision of situations linked to the lack of integration, to urban stigmas and to the presence of communities in conditions of conflict, all operating in conditions of urban conflict.

A brief preliminary survey on the working groups' profile

TABLE I. NUMBER AND MAIN CATEGORIES OF PARTICIPANTS AS A PERCENTAGE OF THE TOTAL

\begin{tabular}{|c|c|c|c|c|c|c|}
\hline Cities & $\begin{array}{l}\text { Total } n^{\circ} \text { of } \\
\text { Participant }\end{array}$ & Social workers & $\begin{array}{c}\text { Principals and } \\
\text { Teachers }\end{array}$ & $\begin{array}{l}\text { Cultural and } \\
\text { linguistic } \\
\text { mediator }\end{array}$ & $\begin{array}{c}\text { Other figures of } \\
\text { migrant } \\
\text { reception }\end{array}$ & Others \\
\hline Caltanissetta & 48 & $27 \%$ & $6 \%$ & $19 \%$ & $25 \%$ & $23 \%$ \\
\hline Catania & 39 & $28 \%$ & $26 \%$ & $3 \%$ & $20 \%$ & $23 \%$ \\
\hline Palermo & 60 & $40 \%$ & - & $10 \%$ & $24 \%$ & $26 \%$ \\
\hline Ragusa & 31 & $13 \%$ & $23 \%$ & $10 \%$ & $13 \%$ & $41 \%$ \\
\hline Total & 178 & & & & & \\
\hline
\end{tabular}


has proved that none of the participants had ever worked on the reorganization of spaces for reception or integration, but all had already managed situations in which the life space of the subjects "treated" in their activities occupied a significant part in individual and social behavior.

\section{B. Experimentation}

At this point, the groups were involved in a workshop that was structured trying to give answers to the theoretical questions addressed and the starting condition that the groups of experts had lived.

The aim of the laboratory was therefore to simulate urban intervention strategies to improve integration: the choice of a public space through a strategic approach to the chosen place is followed by the analysis of the state of affairs - urban and sociological - and the right to draw a set of strategic actions adapted to the social condition of the target groups of the project and consistent with the chosen place. During laboratory activities, it was forbidden for the working groups specifically set up with a mix of the figures - to introduce social policy activities that did not have a suitable location and, therefore, did not fit the chosen place.

The output produced by the various groups was a set of urban strategies for integration, in which the strategic axes of work were clearly explained, probably in reference to already active national or local policies, priority actions and "flag" projects, namely projects able to make others appreciate the results and that could act as a flywheel compared to the overall results of the experimentation.

From the month of January, therefore, the four offices of Caltanissetta, Catania, Palermo and Ragusa have undertaken an activity in two phases and with different workloads depending on the characteristics of the place and the structure that acted as a facilitator of the activities:

- simulation activities in the classroom, in cooperative learning;

- field experimentation activities often connected with the sensitization produced during the simulation phase.

The places taken into consideration have very similar characteristics in terms of nature and urban location. Only Palermo works mainly on more classical suburban conditions.

The recurring themes are food and sport, understood as temporary activities that substantiate the urban space and bring life even where places are not specifically designed.

\section{Places and project visions}

Four cities for project visions in urban resilience and migrant integration: this is the idea on which the experimentation is based. Every workgroup selected places and visions summarized here:

- Caltanissetta. The urban garden is a meeting place for foreign communities, but also a place for illegal activities. The urban / social intervention hypothesis foresees, in interlocution with the Municipal Administration, the elimination of the garden fence and the realization of socialization activities for the "new" citizens;

- Catania. "La Civita" has been for years a multicultural district, on Piazza Cutelli overlooking the National Boarding School, the School of Political Sciences of the University of Catania and the city mosque. The multiplicity of functions and their apparent lack of homogeneity is the fulcrum for the development of the idea of opening the boarding school during extra-school hours, which thanks to its accommodation capacity and catering could host the temporary school of kitchens from the world;

- Catania. San Berillo and the void space of Viale Martiri della Libertà. The center of the intervention by social and urban policies is not in the great void considered by Mario Cucinella, but it is the fabric in the north, where Senegalese families live, often doing domestic food, not authorized, but with a strong vocation to intercultural sharing. The project aims at the emergence of this submerged activity and its characterization, while awaiting the major urban redevelopment project that will surely change the cards on the table;

- Palermo. San Filippo Neri (ZEN). Once the stigma has been overcome, there are many activities that social workers have started and, therefore, the experimental hypothesis of the laboratory aims to recreate various activities, starting from RedPoint opened by SaveTheChildren. Children are the center of the urban / social redevelopment hypothesis (see also the activities carried out by the Department of Architecture of UNIPA, together with the Municipality and other nonprofit organizations) [13];

- Ragusa. The belvedere that serves as a backdrop to Via Roma, little exploited as a social space, is in the middle of a district that is gradually becoming populated by new foreign citizens. The latter, thanks also to the services available at the Multipurpose Center for Immigration of Ragusa, choose the city as a new residence. The aim of the project is to give rise to social functions, which are already largely carried out at the Multifunctional Center, inside new spaces of great symbolic value, such as the belvedere;

- Ragusa. The Piazza Carmine area, with its large convent building not in use, is the ideal place to bring many activities concentrated in the Multipurpose Center into the historical center, adding also the theme of the market, traditionally present in the neighborhood name (putie, in Italian botteghe) but no longer present.

\section{CONCLUSIONS}

The results of the activities carried out are already evident in the operational repercussions on many of the sites, where the presence of a specific structure, for example the Multipurpose Center for Immigration of Ragusa, already acts as a router for integration activities at the local level, carrying out activities of 
facilitation to the planning and at the same time equipping spaces and carrying out activities for socialization [14].

The number of the activities of the Multipurpose Center for Immigration of Ragusa, from February to May 2018, that is from the beginning of the survey linked to the experimentation, proves this step forward: seven activities carried out at the headquarters or in other places of the city of Ragusa starting from sporting events, social gardens, cuisine, film club, health and participation.

In addition, more than ten suggestions for calls for proposals and design in the field of participation and inclusion for the same communities and non-profit organizations of the Multifunctional Center network were conveyed to the associations and local communities.

In conclusion, the research activity which today awaits the feedback from the other laboratories finds in Ragusa a very specific situation due to proximity to the border problem and the presence of a structure already equipped to overcome difficulties in the field of social policies. The center in Ragusa begins to show that working in the urban regeneration sector, dealing with the themes of integration and multiculturalism, is not to be taken for granted even where social workers are active.

The study seems to demonstrate that social action and urban renewal remain two separate areas, both in the framework of training of professional figures (see the results of the reflection of laboratories in cooperative learning) and within the urban policy of recovery of degradation and of marginality.

Applied research finds its success in a method, additional to social policies, based on listening and cultural mediation, summarized here in some key points:

- new communities and social workers must ask and identify places to express identities, meet and recognize each other;

- the socialization function linked to the culture of food and market is the main theme of the self-recognition of the communities;

- the presence - where possible - of an urban symbolism that materializes the aspirations of the community or recollects their origin and cultural background;
- play and sport, often linked to the culture of origin of the community, contribute to the structuring of this sense of recognition.

The method adopted is therefore linked to a principle of urban resilience that aims to support the occupation of unused spaces, but the concept of integration must contribute to the definition of a minimum set of actions for the construction of collective interest through the selection of equal opportunities, sense of community and social responsibility and strengthening of public spaces.

[1] A. Amin, N. Thrift, Città. Ripensare la dimensione urbana. Bologna, Il Mulino, 2005

[2] K. Tajbakhsh, The Promise of the City: Space, Identity, and Politics in Contemporary Social Thought. Berkeley (CA-USA), University of California Press, 2001

[3] C.S. Holling, "Resilience and Stability of Ecological Systems", Annual Review of Ecology and Systematics, 4, 1973, pp. 1-23

[4] C. Folke, "Resilience: The emergence of a perspective for socialecological systems analyses". Global Environmental Change, 16/3, 2006, pp. 253-267.

[5] S. Carpenter, B. Walker, J.M. Anderies, N. Abel, "From Metaphor to Measurement: Resilience of What to What?", Ecosystems, 4, 2001, pp. 765-781.

[6] M. Scheffer, Critical Transitions in Nature and Society, Princeton, Princeton University Press, 2009

[7] P. O'Hare, I. White "Deconstructing resilience: Lessons from Planning Practice". Planning Practice \& Research, 28(3), 2013, pp. 275-279

[8] S.T.A. Pickett, M.L. Cadenasso, J.M. Grove, "Resilient cities: meaning, models, and metaphor for integrating the ecological, socioeconomic, and planning realms". Landscape and Urban Planning, 69, 2004, pp. 369-384

[9] UN Habitat, Trends in urban resilience, annual report. Nairobi, 2017

[10] M. Aymard, "Storie di piazze, piazze nella storia", in Mancuso F. (a cura di), La piazza nella città europea. Luoghi, paradigmi, buone pratiche di progettazione. Padova, Il Poligrafo, 2012

[11] D. Weinberger D, Too Big to Know: Rethinking Knowledge Now That the Facts Aren't the Facts, Experts Are Everywhere, and the Smartest Person in the Room Is the Room. New York (NY, USA), Basic Books 2011

[12] M. Carta M, B. Lino, D. Ronsivalle, Re-Cyclical Urbanism. Visions, paradigms and Projects for the Circular Metamorphosis. Trento, Listlab, 2017, p. 176-187

[13] M. Picone, F. Schilleci (a cura di), QUID. Quartiere e Identità. Per una rilettura del decentramento a Palermo. Firenze, Alinea 2012

[14] H. Casanova, J. Hernadez, Public Space Acupuncture: Strategies and Interventions for Activating City Life. New York (NY-USA), Actar Publishers, 2014 